\title{
Estratégia quirúrgica en el carcinoma de células renales con extensión a la circulación venosa
}

\author{
D. García Ortells*, E. Fernández Fernández*, E. de Vicente**, A. Honrubia***, J.L. Moya****, \\ V. Abella*****, Á. Escudero Barrilero* \\ *Servicio de Urología. **Servicio de Cirugía General y Digestivo (Unidad Trasplante hepático). \\ ${ }^{* * *}$ Servicio Cirugía Cardiaca. ${ }^{* * * *}$ Servicio Cardiología (Unidad de Ecocardiografía). \\ *****Servicio Anestesia. Hospital Ramón y Cajal. Madrid. \\ Actas Urol Esp 2005; 29 (5): 448-456
}

\section{RESUMEN \\ ESTRATÉGIA QUIRÚRGICA EN EL CARCINOMA DE CÉLULAS RENALES CON EXTENSIÓN A LA CIRCULACIÓN VENOSA}

$\mathrm{El}$ carcinoma de células renales con trombo en vena cava inferior es una patología relativamente rara, que complica la nefrectomía radical. Durante los pasados veinte años nuestro hospital ha contribuido sustancialmente a la estratificación quirúrgica del carcinoma de células renales con extensión a la vena cava a través de diferentes técnicas. El objetivo de este artículo es describir las diferentes estrategias quirúrgicas necesarias y más apropiadas para el tratamiento de los distintos niveles del trombo tumoral. Consideramos que el diagnóstico de la invasión de la vena cava por el tumor y el nivel de extensión tumoral están basados en exámenes radiológicos, los cuales son determinantes a la hora del planteamiento quirúrgico y éxito de la cirugía. Somos partidarios del uso de filtros de vena cava colocados.preoperatoriamente para prevenir el riesgo de tromboembolismos pulmonares durante y después de la cirugía. El uso de prótesis de cava es excepcional, debido a que la obstrucción crónica producida por el trombo tumoral, permitirá el desarrollo de una extensa circulación colateral que actuará como un bypass veno-venoso. Por último, intentamos evitar el uso de bypass veno-venoso o bypass cardiopulmonar con o sin hipotermia y parada cardiocirculatoria, debido a la alta morbimortalidad que conllevan.

Palabras clave: Trombo tumoral. Adenocarcinoma de células renales. Nefrectomía radical.

\section{ABSTRACT}

\section{SURGICAL STRATIFICATION OF RENAL CARCINOMA WITH EXTENSION INTO INFERIOR VENA CAVA}

Renal cell carcinoma with inferior vena cava thrombus is relatively uncommon and complicates radical nefrectomy. During the past twenty years our hospital have substantially contributed to the surgical stratification of renal cell carcinoma with extension into inferior vena cava through different techniques. The reason for this article is to discuss the more efficient and appropiate surgical technique for this pathology. We believe that the diagnosis of vena caval invasion and level of tumoral extension is based on radiological examinations and it is crucial for the success of the surgery. We consider that the use of vena caval filter applied preoperatively could prevent the risk of thromboembolism during and after the surgery. The use of prosthetic grafts is unusual, because the long standing obstruction caused by the tumor thrombus will develope extensive collateral circulation which works as a natural veno-venous bypass. Finally, we try to avoid the use of veno-venous and cardiopulmonar bypass with or without complete hypothermic circulatory arrest due to the high association with adverse outcomes and mortality. 
$\mathrm{E}_{\mathrm{p}}^{1}$ carcinoma de células renales es una patología poco frecuente que corresponde al $2 \%$ de todos los cánceres del adulto ${ }^{1}$. Representa el tercer tumor en frecuencia dentro de los cánceres urológicos. La diseminación más característica de este tumor se realiza a través del sistema venoso, siendo frecuente la formación de trombos venosos tumorales, que progresan a través de la vena renal hasta la vena cava inferior, pudiendo llegar en ocasiones a la aurícula derecha. Ya en el momento del diagnóstico podemos encontrar invasión de la vena renal en el 20-35\% de los adenocarcinomas de riñón. La extensión a la vena cava inferior se desarrolla del 4-10\% de los pacientes y en $10-25 \%$ de estos se presenta propagación del trombo tumoral sobre las venas suprahepáticas hasta la aurícula derecha o incluso ventrículo derecho ${ }^{2}$. $\mathrm{El} 30-40 \%$ de los pacientes presentan adenopatías o metástasis a distancia al diagnóstico. Pacientes con carcinoma renal, trombosis venosa tumoral y sin presencia de metástasis de distancia sometidos a nefrectomía radical y trombectomía, presentan supervivencias del $30-72 \%$ a los cinco años de seguimiento ${ }^{3,4}$. La proporción de la incidencia en varones en comparación con las mujeres es de 4:1. Los enfermos con afectación de la vena cava pueden presentar signos como consecuencia de la obstrucción, aunque en la mayoría de las ocasiones el trombo no es totalmente obstructivo o se ha desarrollado suficiente circulación colateral. En pocas ocasiones se presentan manifestaciones clínicas como embolismos pulmonares recurrentes, edema de miembros inferiores, disfunción hepática o renal, malabsorción, varicocele, etc., que pueden indicar una completa oclusión de la vena cava inferior por el trombo tumoral.

La extensión intracava del tumor es bastante única, porque en la mayoría de los casos, simple- mente se extiende a lo largo de la vena cava sin infiltrar la pared de la misma. Aunque históricamente se ha considerado la presencia del trombo tumoral un factor de mal pronóstico, recientes estudios indican que la simple presencia del trombo tumoral no ha demostrado ser determinante en la supervivencia siempre y cuando sea tratado quirúrgicamente ${ }^{4-7}$. La total resección del tumor ofrece la única opción de obtener una supervivencia a largo plazo sin la presencia de metástasis a distancia. Incluso, recientes estudios recomiendan tratamiento quirúrgico con la presencia de metástasis a distancia ${ }^{7}$.

El diagnóstico de la invasión de la vena cava y el nivel de la extensión del trombo tumoral son determinantes importantes a la hora del planteamiento quirúrgico, los cuales están basados en técnicas de imagen. Esta es la razón por la cual el diagnostico de la invasión de la vena cava por el tumor esta basado en exámenes radiológicos ${ }^{7}$. La RNM ha demostrado ser la técnica de imagen con mayor grado de fiabilidad para determinar la extensión craneal del trombo tumoral, así como establecer la invasión de la pared vascular por el tumor. La asociación de la TAC y RNM alcanzan un valor predictivo del $100 \%$. El estudio vascular (cavografía) ha quedado, en la actualidad, relegado por la presencia de técnicas radiológicas menos invasivas que ofrecen una excelente información sobre la afectación vascular. El TAC tridimensional aporta información sobre el estado de la circulación colateral. La ecocardiografía transesofágica pre e intraoperatoria es de gran utilidad para confirmar la extensión y movilidad del trombo (Tabla 1). El margen superior del trombo tumoral en el interior de la vena cava inferior es la base de la clasificación y es crucial a la hora del planteamiento quirúrgico, el cual es técnicamente complejo y puede estar asociada con una morbilidad y mortalidad elevadas (Figs. 1, 2, 3 y 4).

\section{Tabla 1}

Utilidad de la Ecocardiografía.

\begin{tabular}{ll}
\hline Precirugía & Intraoperatoria \\
Afección y extensión del trombo en aurícula derecha & Precisar la lesión. Información adicional: defectos no sospechados \\
Crecimiento de la aurícula derecha & Guía de la intervención \\
Infiltración de aurícula derecha & Confirmar el resultado de la extracción del trombo. \\
Movilidad del trombo en aurícula derecha & Detección de complicaciones quirúrgicas o hemodinámicas \\
\hline
\end{tabular}




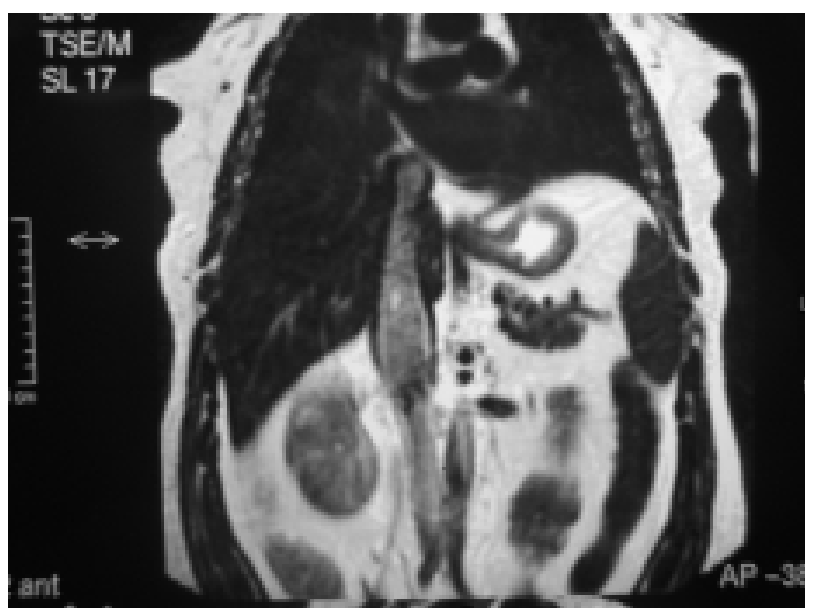

FIGURA 1. RNM con trombo en cava.

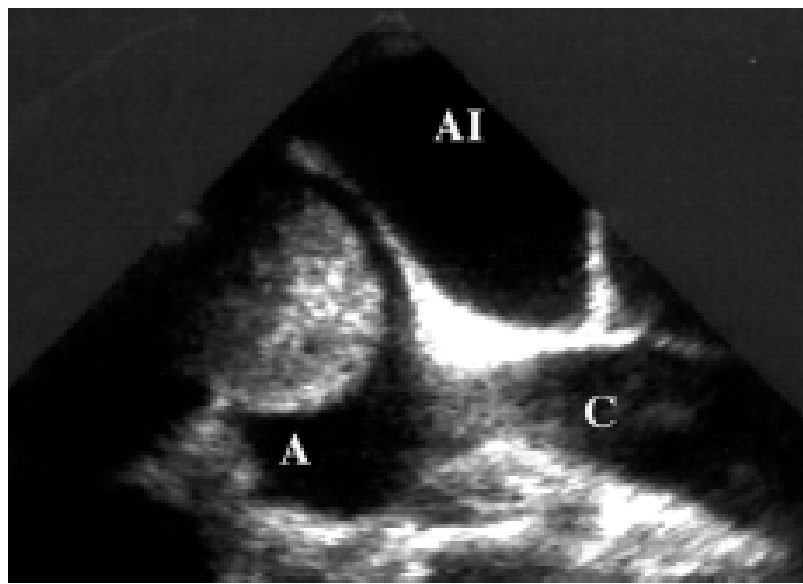

FIGURA 2. Ecocardiografia con trombo en auricula.

\section{TECNICA QUIRURGICA}

El objetivo principal de la intervención quirúrgica para el tratamiento de pacientes con Carcinoma de células renales asociado a extensión intracava es la completa extirpación de la lesión renal y del trombo tumoral. La dificultad de la nefrectomía radical se incrementa con la presencia del trombo tumoral en la vena cava inferior. Varias técnicas quirúrgicas han sido descritas para afrontar este problema, incluyendo bypass venovenoso y cardiopulmonar. Recientemente la utilización de maniobras quirúrgicas utilizadas en el transplante hepático han permitido evitar el uso de técnicas de bypass. El extremo cefálico del trombo es la base de la clasificación y diferentes intervenciones han sido descritas dependiendo de la extensión proximal del trombo. Tradicionalmente se establecen varios niveles quirúrgicos:
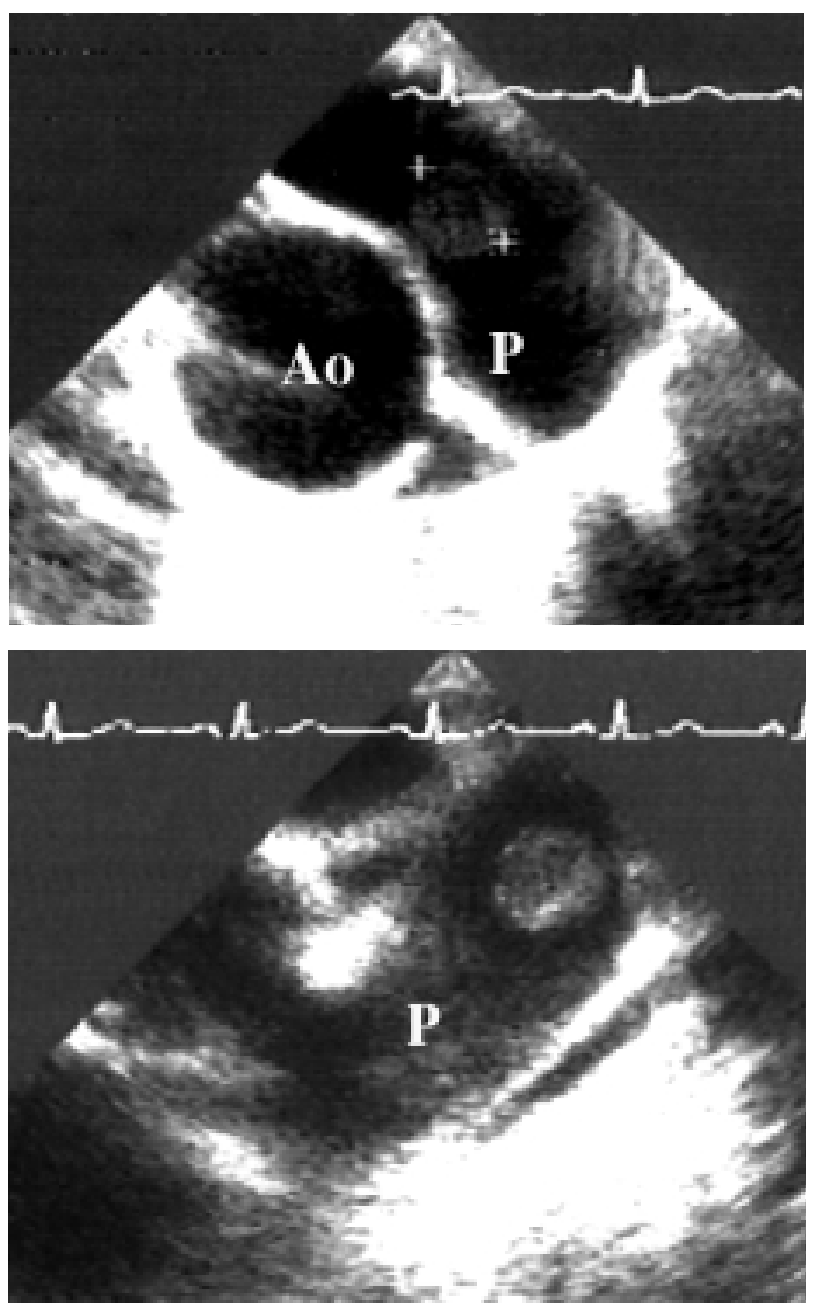

FIGURA 3. Ecocardiografia con trombo en arteria pulmonar.

- Nivel I: Trombo en vena renal y vena cava infrahepática.

- Nivel II: Trombo en vena cava retrohepática sin alcanzar las venas suprahepáticas

- Nivel III: Trombo infradiafragmático, por encima de venas suprahepáticas.

- Nivel IV: 1 . Trombo insinuándose $2-3 \mathrm{~cm}$ en la aurícula derecha.

2. Trombo que ocupa toda la aurícula derecha.

El éxito del procedimiento dependerá del conocimiento preciso de la localización del trombo, del diseño de una estrategia quirúrgica adecuada a los hallazgos radiológicos y de la experiencia quirúrgica multidisciplinar para acceder y tratar el problema preferentemente por vía abdominal. 


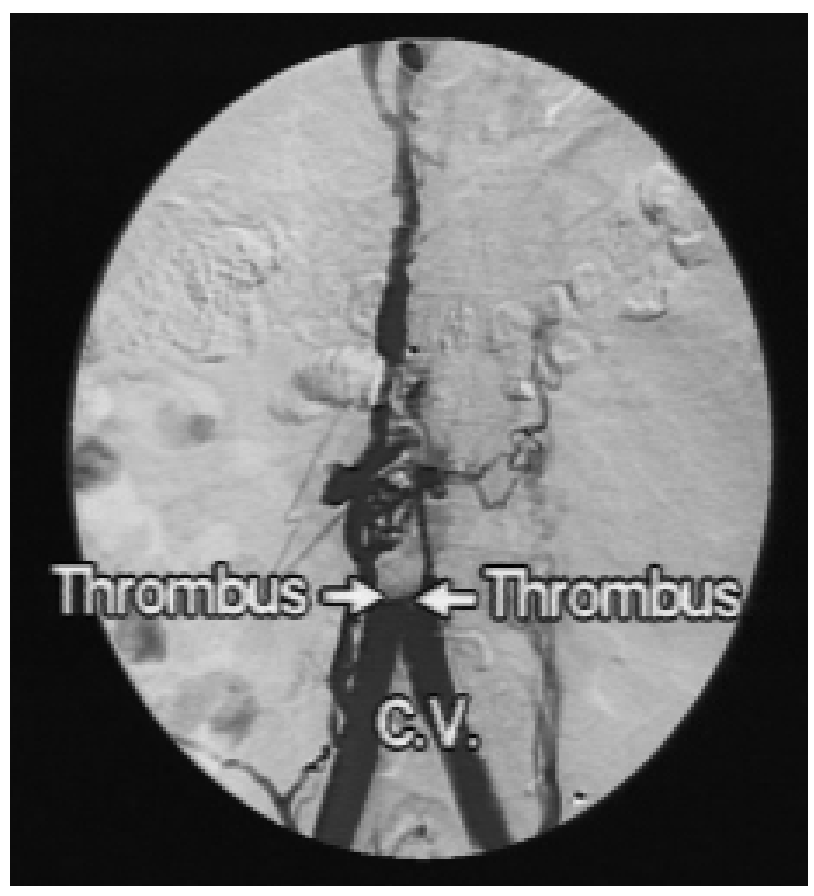

FIGURA 4. Cavogafrafia.

\section{Nivel I}

Se practica siempre un abordaje abdominal con una incisión a dos traveses de dedos del reborde costal. No es preciso en este nivel una incisión toracoabdominal. Se lleva a cabo, en el lado derecho una amplia maniobra de Kocher hasta exponer la vena cava y renal derecha. En el lado izquierdo, debe seccionarse el peritoneo posterior y el ligamento esplenorrenal para movilizar en sentido medial y hacia abajo el colon descendente; y en sentido medial y hacia arriba el páncreas y el bazo. Independientemente del nivel del trombo, se debe ligar la arteria renal en primer lugar, adecuado control de la vena cava y evitar la manipulación venosa previamente al clampaje de la vena por encima del trombo. Es esencial obtener un control de la vena cava inferior por encima del trombo antes de cualquier manipulación de la masa tumoral intracava, para prevenir embolismos intraoperatorios de fragmentos tumorales ${ }^{7}$. Cuando el nivel de la extensión vascular del carcinoma de células renales afecta solo a la vena renal es suficiente el clampaje de la vena a nivel del ostium. Se realiza, a continuación, cavotomía y extracción del trombo tumoral de forma sencilla por tratarse de un trombo blando, friable y excepcionalmente adherido a la pared de la vena. La localización del trombo a dicho nivel no exige movilización hepática $y$ las modificaciones hemodinámicas al clampaje de la vena cava son irrelevantes.

\section{Nivel II:}

Cualquier trombo localizado en la porción retrohepática de la vena cava o craneal a esta, requiere una adecuada exposición y control de las mismas como factor clave de éxito en la cirugía. A partir de este nivel consideramos conveniente la colaboración con cirujanos hepáticos expertos para su movilización y exposición de la vena cava superior.

Se debe practicar una laparotomía subcostal bilateral a unos dos traveses de dedo del reborde costal. La dificultad del abordaje hepático, puede obligar en determinados casos a la realización de una prolongación medial hasta alcanzar la apófisis xifoides. Un retractor de Rochard es utilizado el cual eleva el reborde costal. Para llevar a cabo esta exposición es imperativo la movilización hepática, la cual debe ser muy cuidadosa por la masiva formación de circulación colateral creada por la obstrucción crónica de la vena cava inferior por el trombo tumoral, dejando como única estructura de anclaje del hígado el hilio hepático con sus estructuras vasculares; arteria hepática, vena porta y venas hepáticas. Además de la separación del hígado de la vena cava inferior con la ligadura de pequeñas venas colaterales en la mayoría de los casos trombosadas por el proceso trombótico, la liberación de la vena cava inferior y del retroperitoneo en su cara posterior, son muy importantes para conseguir un control vascular de la misma. Cuando el nivel de la extensión vascular del carcinoma de células renales es inferior al hígado, es suficiente el control (mediante clampaje) proximal y distal de la vena cava junto al de la vena renal contralateral. Se realiza, a continuación, cavotomía y extracción del trombo tumoral. Es trascendental conocer previamente y apreciar intraoperatoriamente el nivel proximal y distal del trombo a efectos de colocar el clamp vascular en el sitio preciso, evitando fragmentaciones del trombo que podría provocar embolismos pulmonares.

Es importante conocer el drenaje venoso colateral porque en ocasiones puede ser necesaria la 
utilización de una resección parcial de la vena cava, con la consiguiente colocación de un parche de cava. En ocasiones también puede ser útil la colocación de filtros de vena cava (definitivos extraíbles) colocados por encima de los vasos renales y por debajo de las venas suprahepáticas para evitar embolismos intraoperatorios durante la manipulación del tumor. Como se señalará más adelante, no suele ser necesaria la colocación de un prótesis de cava, ya que la circulación colateral provocada por la obstrucción crónica del trombo, suele ser suficiente para asegurar el retorno venoso (Figs. 5 y 6).

\section{Nivel III}

Cuando el trombo se localiza por encima de la salida de las venas suprahepáticas también se puede practicar una incisión de las mismas características a las descritas previamente. Las áreas femoral y axilar deben de ser preparadas dentro del campo quirúrgico, para permitir acceso a la vena femoral y axilar, ante la necesidad de practicar un bypass veno-venoso, técnica introducida en 1984 por Shaw, cuyas ventajas están documentadas en el transplante hepático ortotópico $^{8}$. El uso de bypass veno-venoso no está exento de riesgo; pueden aparecer complicaciones como linfocele, infección y lesión de vasos femorales, axilares y aurícula así como embolia gaseosa $^{9}$. En nuestro centro no consideramos la
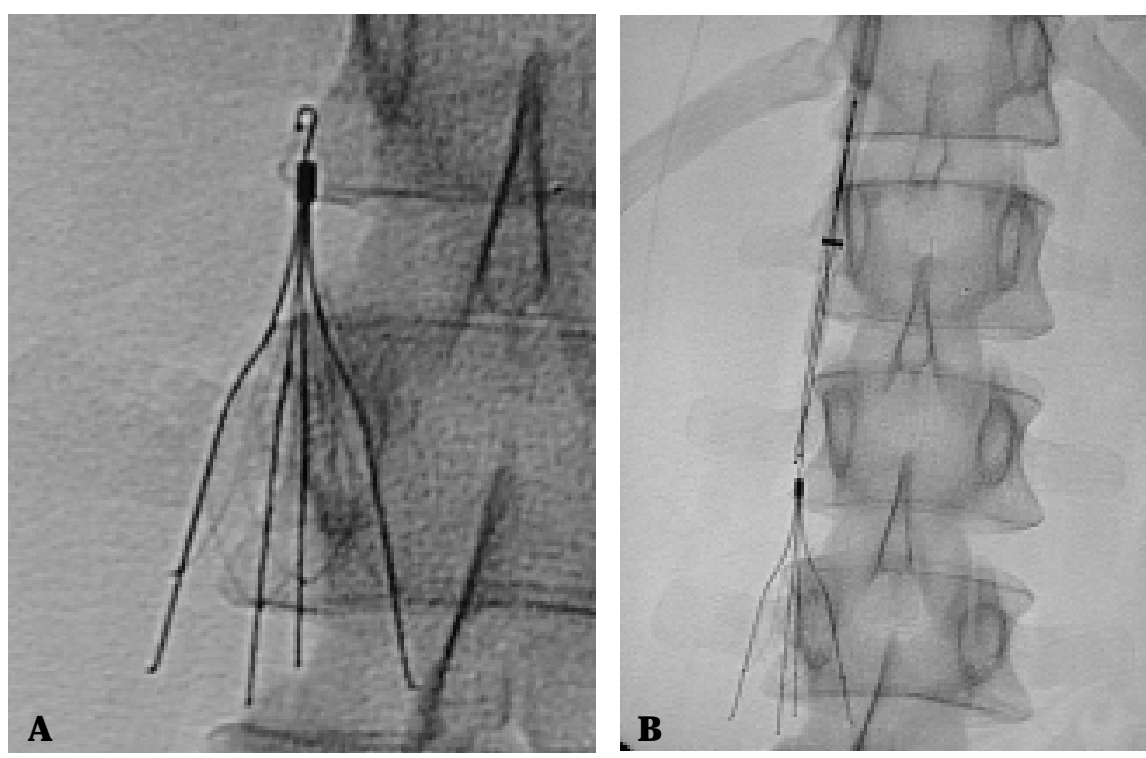

FIGURA 5. A. Filtro de vena cava. B. Procedimiento de extracción del filtro. necesidad de este tipo de bypass, ya que el retorno venoso queda asegurado por la extensa circulación colateral, producida por la obstrucción crónica motivada por el trombo tumoral, actuando como un bypass natural.

Una vez expuesta la vena cava inferior retrohepática en toda su longitud, con la ayuda indispensable de cirujanos hepáticos expertos, se identifican y liberan las venas hepáticas, a efectos de efectuar una exclusión vascular selectiva hepática. Posteriormente se lleva a cabo una maniobra de Pringle, provocando una obstrucción temporal del flujo hepático "de entrada", mediante el clampaje de la artería hepática y de la vena porta, con el motivo de disminuir el flujo sanguíneo a nivel del hígado. La vena cava infrarrenal, vena renal contralateral y venas suprahepáticas son clampadas en este orden. Durante esta fase anhepática de la cirugía, en la cual el flujo cavo está mantenido, es poco frecuente que aparezcan trastornos hemodinámicos derivados de la disminución del retorno venoso portal y sistémico al corazón, provocados por el clampaje de la venas suprahepáticas y cava inferior. Una complicación esperada sería el fracaso renal agudo postoperatorio secundario al clampaje de la vena renal. Esta complicación disminuye considerablemente debido a la alta colateralidad a dicho nivel. Como indica Golimbu et al. está técnica no requiere de una completa heparinización evitando así riesgo de sangra$\mathrm{do}^{20}$. El uso de esta oclusión temporal del flujo hepático a la vena cava, puede provocar una congestión venosa en el intestino, especialmente si se prolonga por un período de tiempo superior a la hora. La crónica obliteración de la vena cava inferior por el trombo va a inducir circulación colateral a través de las venas lumbares, sistema ácigos/hemiácigos y venas testiculares y ováricas. Para algunos autores el uso de este natural bypass veno-venoso puede prevenir el uso de cualquier otro tipo de bypass, por lo que esta circulación colateral debe ser 


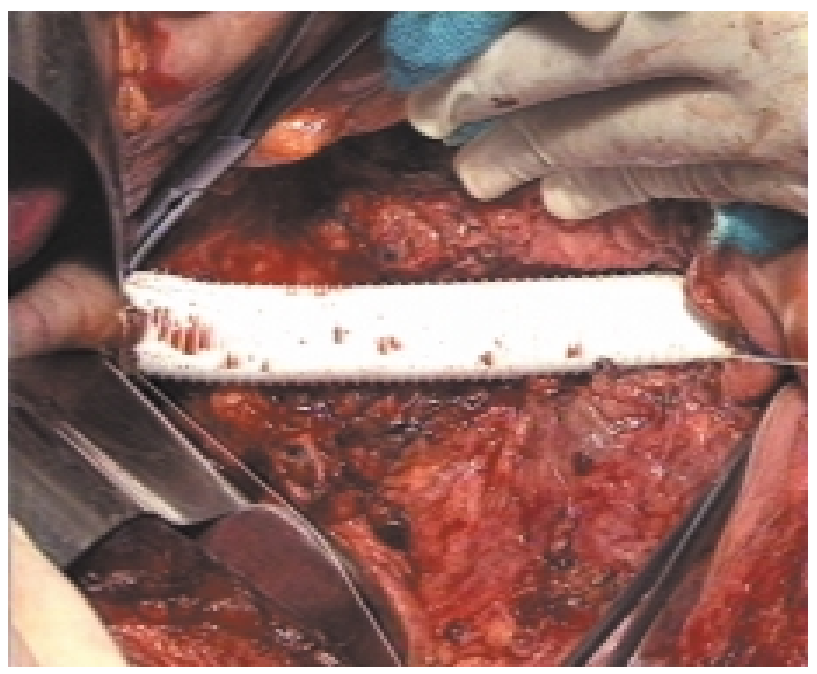

FIGURA 6. Foto parche de cava.

preservada durante la cirugía ${ }^{11}$. Una vez disecada la vena cava inferior se realiza una cavotomía a lo largo de su cara anterolateral por debajo de las venas hepáticas y se extrae el trombo tumoral en bloque así como el tejido adherido a la superficie endotelial. El cierre de la cavotomía se empieza proximalmente. Una vez suturado por debajo de las venas suprahepáticas, se coloca el clamp vascular por debajo de estas. Se libera la maniobra de Pringle y el clampaje de las venas suprahepáticas minimizando el tiempo de isquemia del hígado. Cuando la vena cava infrarrenal es suturada, el clamp vascular es recolocado para permitir el drenaje de la vena renal contralateral. Una técnica útil, es exprimir manualmente el trombo en dirección caudal para situarlo por debajo de las principales venas hepáticas, aplicando un clamp vascular por debajo de estas venas. Con esto se consigue que las venas hepáticas puedan seguir drenando a la vena cava inferior y no comprometer el retorno venoso al corazón. Un control ecográfico intraoperatorio facilita el conocimiento del límite proximal y distal del trombo (Fig. 7)

\section{Nivel IV:}

Cuando el trombo se sitúa a este nivel, el manejo quirúrgico ha de individualizarse. Aconsejamos la intervención en un ambiente con presencia de cirujanos hepáticos, cirujanos cardíacos por la eventual necesidad de bypass cardiopulmonar con circulación extracorpórea con o sin necesidad de parada cardiaca. El uso de bypass cardiopulmonar conlleva riesgos como disfunción plaquetaria, shock hemorrágico, lesiones neurológicas, dehiscencia o infección de la esternotomía y coagulopatía por la necesidad de anticoagulación en este tipo de bypass ${ }^{10}$. La esternotomía, atriotomía, parada cardiaca, hipotermia y recuperación de sangre aumenta la morbimortalidad de esta cirugía, alcanzando un 50\% cuando el trombo alcanza la aurícula derecha ${ }^{12}$. El motivo del uso de un bypass y parada cardiaca es la extracción del trombo en un campo quirúrgico exangüe ${ }^{7}$. Sin embargo, consideramos que los pequeños trombos que se insinúan en la aurícula, en la vena cava inferior infradiafragmática o a nivel de las venas suprahepáticas no necesitan de esta técnica. El bypass cardiopulmonar requiere una completa heparinización con posibilidad importante de sangrado, agravado por el amplio lecho quirúrgico de la nefrectomía radical. Como alternativa se ha utilizado el bypass veno-venoso ${ }^{21}$ aunque en nuestra experiencia nunca ha sido empleado cuando el trombo se ha situado a nivel de venas suprahepáticas o se ha insinuado en la aurícula. El bypass cardiopulmonar se debería reservar para aquellos casos en los que no es posible una adecuada visualización de la trombectomía, un adecuado desplazamiento caudal del trombo o el trombo está adherido a la pared de la aurícula.

Nosotros intentamos evitar el uso de bypass veno-venoso y bypass cardiopulmonar. La técnica quirúrgica se lleva acabo de manera similar al

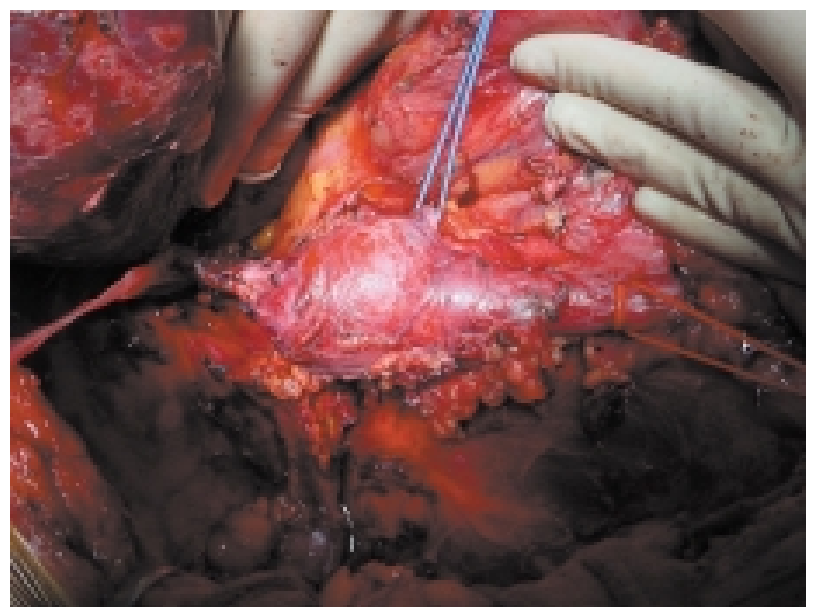

FIGURA 7. Vena cava retrohepática. 
apartado anterior, pero para alcanzar la porción intrapericárdica de la vena cava inferior es necesaria la apertura diafragmática mediante una sección en la línea media del hiato de la vena cava inferior. De forma similar a la descrita en el apartado anterior una vez expuesta la porción retrohepática de la vena cava gracias a la movilización hepática se colocan clamps vasculares a nivel de las venas suprahepáticas, vena cava infrarrenal y vena renal contralateral. Se procede entonces a exprimir el trombo desde la aurícula en sentido caudal hasta la vena cava suprahepática y se coloca otro clamp vascular a este nivel, para evitar la esternotomía, el bypass cardiopulmonar y los riesgos asociados. Se realiza a continuación la cavotomía y extracción del trombo como en el apartado anterior. Es indispensable pues, cuando el trombo se extiende por encima de las venas suprahepáticas ${ }^{13}$, la realización de una ecocardiografía transesofágica intraoperatoria para confirmar la extensión, movilidad del trombo y la completa extirpación del mismo. Si el trombo no es móvil o es de gran tamaño, lo que dificulta que sea exprimido, se debe realizar bypass cardiopulmonar. Durante este, se realiza esternotomía y una atriotomía para examinar el interior de la aurícula derecha y confirmar la presencia de trombo tumoral adherido en su interior. Una vez confirmada su extensión, se toma la decisión de bypass cardiopulmonar, hipotermia profunda y detención circulatoria. La arteria aorta, la porción de la vena cava inferior por debajo del trombo y la aurícula derecha son canuladas para la posible realización del bypass cardiopulmonar. Varios centros son contrarios a la maniobra de exprimir manualmente el trombo en dirección caudal, por el riesgo de provocar un embolismo pulmonar ${ }^{7}$, si bien, en nuestra experiencia esto no ocurre si la maniobra es muy cuidadosa y con el adecuado control ecográfico intraoperatorio. Además en el caso de ocurrir un episodio de embolismo en la artería pulmonar, nos encontramos en un ambiente con cirujanos cardíacos para la resolver el problema.

Un aspecto importante a considerar, debido a la formación de circulación colateral por la obstrucción del trombo de la vena cava inferior, que explica la formación de un bypass venovenoso natural, es la posibilidad de realizar una cavectomía (en los casos en los que la vena cava este invadida por el tumor) sin la necesidad de colocación de parches o prótesis de cava . El retorno venoso del riñón contralateral está asegurado por parte de esa neoformación de vasos sanguíneos, a través de venas lumbares, testiculares, ováricas y sistema ácigos/hemiácigos ${ }^{11}$. Si se utiliza prótesis sustitutiva de la vena cava inferior, es necesario la realización de una fístula arterio-venosa safeno-femoral a nivel inguinal a efectos de controlar el flujo en el injerto vascular (prótesis anillada) y reducir el riesgo de trombosis del mismo.

\section{DISCUSIÓN}

En 1913, Berg describió la primera nefrectomía y cavotomía para el tratamiento del carcinoma renal que se extendía a la vena cava $^{7}$. Posteriormente en 1970 Marshall et al describieron una pequeña serie de cirugías de carcinomas de células renales asociados a trombosis de la vena cava ${ }^{10}$. Sin embargo, ellos consideraban que el pronóstico en estos pacientes con trombo tumoral era infausto. Posteriormente Skinner et al señalaron que supervivencias prolongadas eran posibles en pacientes con la enfermedad completamente extirpada, con supervivencias superiores a un $55 \%$ en 5 años de seguimiento ${ }^{9}$. Desde entonces, el manejo óptimo de estos tumores ha permanecido controvertido.

La mortalidad intraoperatoría de esta intervención varía según las series de un 6-9\% de los casos. Las causas más frecuentes son el TEP masivo, infarto agudo de miocardio en relación con la CEC y la hemorragia ${ }^{5,16}$. En los casos en los que el trombo tumoral alcanza la aurícula derecha la mortalidad puede llegar al 50\%.La supervivencia global a 5 años, en pacientes sometidos a nefrectomía radical sin la presencia de metástasis a distancia, varía según la literatura entre un $30-72 \%{ }^{4}$.

El diagnóstico de pacientes con carcinoma de células renales con trombosis tumoral ha sido desde siempre difícil de predecir debido a una amplia variedad de comportamientos clínicos. Es sabido que cuando se presenta la trombosis tumoral en estas neoplasias, si los pacientes no son tratados, cabe esperar bajos índices de super- 
vivencia $^{7}$. Sosa y colaboradores reseñaron que pacientes sometidos a nefrectomía sin extirpar la trombosis tumoral no presentaban supervivencias superiores a 1 año $^{14}$. En 1972, se demostró que la extensión venosa del trombo tumoral era potencialmente curable con supervivencias a los 5 años del $55 \%{ }^{7}$. A partir de entonces, varias investigaciones han señalado que la extensión vascular per se no es indicativo de una mayor agresividad por parte del tumor y que la total extirpación del riñón y del trombo tumoral ofrece la mejor oportunidad curativa y supervivencia a largo plazo cuando no se ha demostrado la existencia de metástasis a distancia. La extirpación de la neoplasia primaria junto con su extensión a la vena cava no solo palia la sintomatología provocada por el tumor, sino que además se extirpa el foco de la enfermedad así como se reduce los problemas asociados tales como coagulopatías y disfunciones hepáticas ${ }^{7}$.

La presencia de invasión tumoral en los ganglios linfáticos regionales y grasa perirrenal es considerado como factor de mal pronóstico ${ }^{15}$. Pacientes con carcinoma de células renales extendiéndose solo a la vena cava inferior tienen mejores índices de supervivencia que aquellos con extensión local del tumor a los ganglios regionales o tejido perirrenal ${ }^{16}$. Pacientes sin evidencia de metástasis a distancia tienen un $60 \%$ de supervivencia en seguimientos de 16 años, mientras que ningún paciente con metástasis a distancia o adenopatías regionales sobrevivió más de 5 años ${ }^{7}$. Pacientes con tumor renal e invasión de la vena cava y sin metástasis no parecen tener diferencias en supervivencia comparados con carcinoma renal e invasión solo de la vena renal $^{17}$. Algunos estudios han sugerido que la presencia de metástasis en el diagnóstico es un signo de muy mal pronóstico, y que una cirugía agresiva no es recomendada en estos pacientes. Sin embargo, recientes estudios concluyen que la presencia de enfermedad metastásica no tiene un efecto adverso en términos de supervivencia, teniendo algunos de estos pacientes prolongados índices de supervivencia por razones inexplicables $7,16,18$. De todas maneras parece existir unanimidad en reconocer que la presencia de metástasis a distancia y ganglionares son los factores pronósticos más determinantes en la supervivencia ${ }^{19}$.
El tumor renal en ocasiones invade la pared de la vena renal y cava, y esta extensión en si es un fiel reflejo de un comportamiento más agresivo por el tumor. Sin embargo, el pronóstico de esta invasión de la pared venosa en el carcinoma de células renales permanece sin esclarecerse. Golimbu y colaboradores concluyeron en un estudio que esta invasión de la vena cava, por si sola no alteraba las supervivencias a 5 años y no notaron diferencias en términos de supervivencia, mientras que otros autores reseñan que esta característica del tumor se asocia con un pronóstico muy pobre $^{20}$. Asímismo, la presencia del síndrome de Budd-Chiari, excepcionalmente presente, como consecuencia de la obstrucción de las venas suprahepáticas, no parece afectar al pronostico, de manera que la presencia de este síndrome o de fallo hepático no debería contraindicar la cirugía ${ }^{12}$, aunque si el riesgo por la asociación de la isquemia hepática a un hígado con éxtasis vascular.

La implicación pronostica del nivel de extensión del trombo tumoral no está aclarada y permanece controvertida. Algunas investigaciones han demostrado peor pronóstico mientras que otras publicaciones no han demostrado diferencias significativas en términos de supervivencia en función del nivel de la extensión del trombo tumoral.

Varias publicaciones has mostrado la importancia de la erradicación completa de la enfermedad, ya que pacientes con resección incompleta del tumor y trombo se relacionan con un peor pronóstico. Hatcher demostró que el pronóstico de la enfermedad estaba determinada por la completa resección quirúrgica y no por el nivel del trombo tumoral ${ }^{15}$.

Como conclusión, a la hora de establecer los factores pronósticos que nos permitan definir el grupo de pacientes que se beneficiarían de la cirugía, los resultados no son uniformes e incluso en muchos casos contradictorios, por lo que la extirpación completa del tumor renal y de su invasión asociada de la vena renal proporciona la mejor oportunidad en términos de supervivencia.

\section{CONCLUSIONES}

- La utilización de técnicas de imagen, no accesibles en todos los centros, es fundamental para el correcto diagnóstico y el éxito de la cirugía. 
- La utilización de filtros de cava colocados prequirúrgicamente para evitar la suelta de trombos es muy poco frecuente si se ha diseñado una correcta estrategia quirúrgica.

- La utilización de prótesis de cava es excepcional, debido al desarrollo de la circulación colateral secundaria a la obstrucción crónica del trombo tumoral, actuando como un bypass veno-venoso natural.

- Consideramos que los trombos tumorales en vena cava inferior tipo I, II y III pueden ser extraídos sin la necesidad de bypass venovenoso ni cardiopulmonar. Solo en determinados casos de tipo IV, es necesario el bypass cardiopulmonar.

- La colaboración interdisciplinaria se hace imprescindible en los niveles II, III y IV.

\section{REFERENCIAS}

1. Landis SH, Murria T, Bolden S, et al. Cancer statistics. CA Cancer J Clin 1999;49:8-31.

2. Skinner DG, Colvin RB, Vermillion CD, Pfister RC, Leadbetter WF. Diagnosis and management of renal cell carcinoma-a clinical and pathology study of 309 cases. Cancer 1971;28:1165-1177.

3. Libertino JA, Burke WE, Zinman L. Long-term results of 71 patients with renal cell carcinoma with venous, vena cava, and atrail extension. J Urol 1990;143; 294 A.

4. Tsui Y, Goto A, Hara I, Ataka K, Yamashita C, Okita Y, Kamidono S. Renal cell carcinoma with extensión of tumor thrombus into the vena cava: Surgical strategy and prognosis. Journal of Vascular Surgery 2001;33(4):789-796.

5. Skinner DG, Pritchett TR, Lieskovsky G, et al. Vena caval involvement by renal cell carcinoma. Surgical resection provides meaningful long-term survival. Ann Surg 1989;219: 387-394.

6. Libertino JA, Zinman L, Watkins E. Long term results of renal cell cancer with extension into inferior vena cava. J Urol 1987;137:21-24.

7. Kaplan S, Ekici S, Dogan R, Demircin M, Ozen H, Pasaoglu I. Surgical manegement of renal cell carcinoma with inferior vena cava tumor thrombus. The American Journal of Surgery 2002;183:292-299.

8. Shaw BW, Martin DJ, Márquez J, et al. Venous byass in clinical liver transplantation. Ann Surg. 1984;200:524-533.

9. Browning AJ, Eardley I, Joyce AD, et al. Percutaneous venovenous bypass in surgery for renal cell carcinoma with associated vena caval tumor thrombus. BJU 1999;83:850.
10. Ciancio G, Hawke C, Soloway M. The use of liver transplant techniques to aid in the surgical management of urological tumors. J Urol. 2000;164(3):665-67.

11. Cianco G., Soloway M. The use of natural veno-venous bypass during surgical treatment of renal cell carcinoma with inferior vena cava thrombus. American Surgeon 2002; 68(5):488-490.

12. Kuczyk MA, Hofner K, Stief CG, Machtens S, Jonas U. Surgical strategy in late-stage renal cell cancer with extracaval extension. Curr Opin Urol 1998;8(3):241-245.

13. Treiger BFG, Humphrey LS, Peterson CV, et al. Transesophageal echocardiography in renal cell carcinoma: an accurate diagnostic technique for intracaval neoplastic extension. J. Urol 1991;145:1138.

14. Sosa RE, Muecke EC, Vaughan ED, McCorron JP. Renal cell carcinoma extending into the inferior vena cava: the prognosis significance of the level of the vena cava involvement. J Urol 1984:132:1097-1100.

15. Hatcher PA, Anderson EE, Paulson DF, et al. Surgical management and prognosis of renal cell carcinoma invading the vena cava. J Urol 1991;145:20-24.

16. Nesbitt JC, Soltero ER, Dinney CP, et al. Surgical management of renal cell carcinoma with inferior vena cava tumor thrombus. Ann Thorac Surg 1997;63:1592-1600.

17. Cianco G, Soloway M. Renal cell carcinoma invading the hepatic veins. Cancer 2001;92(7):1836-1842.

18. Skinner DG, Pritchett TR, Lieskovsky G, et al. Vena cava involvement by renal cell carcinoma. Surgical resection provides meaningful long-term survival. Ann Surg 1989; 210:387-394.

19. Ruibal Moldes M, Alvarez Castelo L, Chantada Abal V, Blanco Diez A, Fernández Rosado E, Gonzalez Martín M, Cirugía del carcinoma renal con trombo tumoral en vena cava-aurícula. Actas Urológicas Españolas 2003;27(7):517523.

20. Golimbu M, Joshi P, Spperber A, et al. Renal cell carcinoma: survival and pronostic factors. Urology 1986;27:291301.

21. Belgrano E, Liguori G, Trombetta C, Siracusano S, Bucci $\mathrm{S}$, Zingone B. Modified pump-driven venous bypass in surgery for renal cell carcinoma involving the inferior vena cava. World J Urol 2002;20:56-58.

D. García Ortells

Secretaría del Servicio de Urología

Hospital Ramón y Cajal de Madrid

Carretera de Colmenar Viejo Km. 9,100

28034 Madrid

(Trabajo recibido el 25 enero de 2005) 